\title{
BESTUURSTYLE IN DIE OPENBARE EN PRIVAATSEKTOR VAN DIE SUID-AFRIKAANSE VOLKSHUISHOUDING
}

\author{
W.S. DE VILLIERS
}

Departement Bedryfsielkunde,

Universiteit van Stellenbosch

\section{VAN W. RAUBENHEIMER}

\author{
Departement Menslike Hulpbronbestuur \\ Randse Afrikaanse Universiteit \\ Johannesburg
}

\begin{abstract}
Management styles in the public and private sector of the South African economy. A questionnaire, consisting of various biographical items and a number of measuring instruments was used to determine whether a difference in management style between organizations in the public and private sector exists. A marked resemblance between the biographical profiles of managers in the public and private sectors was found. No statistically significant difference was found in people orientation in the two sectors. Managers in the private sector however, were inclined to be more authoritarian. To the degree that this phenomenon manifests itself in managerial style, a difference in the management styles of managers in the public and private sectors does exist.
\end{abstract}

\section{OPSOMMING}

' $n$ Vraelys, bestaande uit ' $n$ aantal biografiese items en ander meetinstrumente, is gebruik om te bepaal of ' $n$ verskil in bestuurstyl tussen organisasies in die openbare en privaatsektor bestaan. Resultate dui daarop dat die biografiese profiele van bestuurders in die openbare en privaatsektor ' $\mathrm{n}$ groot mate van ooreenstemming toon. Geen statisties beduidende verskil is gevind in mensoriëntering nie. Bestuurders in die privaatsektor openbaar egter ' $n$ groter mate van outoritarisme. In die mate waarin outoritarisme weerklank vind in die bestuurstyl van bestuurders, kan daar ' $n$ verskil in die bestuurstyle van bestuurders in die privaat- en openbare sektor voorkom.

Bestuur speel 'n sleutelrol om individuele pogings in organisasies te koördineer en te lei tot die bereiking van organisatoriese doelwitte. Navorsing dui daarop dat daar oor 'n breë spektrum van veranderlikes ' $n$ aansienlike verskil bestaan tussen privaat- en openbare sektor organisasies, en dit kan weer aanleiding tot verskille in bestuurspraktyk gee. (Buchele, 1977; Verster, 1980; Starling, 1982; Rainey, Backhoff en Levine, 1976; Murray, 1975).

In die lig van die aard en kenmerke van die bestuursfunksie en bestuurstyle en in die lig van die breë onderskeid wat in die volkshuishouding gemaak word tussen die privaatsektor en die openbare sektor, ontstaan die vraag of daar 'n verskil in bestuurstyl by hierdie twee tipes organisasies bestaan. Indien so 'n verskil wel geïdentifiseer kan word, ontstaan die vraag verder waaraan sodanige verskil toegeskryf sou kon word. Aan die een kant sou dit moontlik die kenmerke (breed gesien) van die bepaalde soort organisasie kan wees en aan die ander kant die eienskappe van die individue (dus ook bestuurders) wat in die organisasie werksaam is. Die moontlikheid dat beide hierdie kragte ' $n$ interaktiewe rol speel, is natuurlik ook nie uitgesluit nie.

Met inagneming van die veranderlikes wat 'n invloed op bestuurstyl uitoefen en met inagneming van die kenmerkende eienskappe van organisasies in die privaat- en openbare sektor, kan verwag word dat die leier in elk van hierdie tipe organisasies 'n kenmerkende bestuurstyl sal openbaar, en moontlik ook merkbare persoonlikheidsverskille sal demonstreer.

Indien hierdie verskille wel bestaan, het dit besondere implikasies vir die mannekragbestuurspraktyk wat in die onderskeie sektore gevolg moet word. 'n Differensiële benadering ten opsigte van onder andere praktyke soos bestuurkeuring, bestuursopleiding en ontwikkeling en prestasiebestuur sou nie uitgesluit wees nie.

Die doel van hierdie ondersoek was om te bepaal of daar ' $n$ verskil tussen die bestuurstyle in die privaat- en openbare sektor bestaan en, indien so 'n verskil geïdentifiseer kan word, om te bepaal watter faktore daarvoor verantwoordelik is.

\section{METODE}

\section{Steekproef}

Die steekproef het uit 325 bestuurders op middel- en seniorbestuursvlak (Peromnes-posvlak 6 en hoër) bestaan, waarvan 142 in die openbare sektor en 183 in die privaatsektor werksaam was. In die lig van die praktiese probleme wat normaalweg met navorsing van hierdie aard ondervind word, was suiwer ewekansige steekproeftrekking nie moontlik nie en moes daar gebruik gemaak word van 'n kombinasie van geriefsteekproefneming, oordeelsteekproefneming en kwotasteekproefneming (vergelyk de Villiers, 1990).

Die bestuurders was werksaam in 'n verskeidenheid van bestuursrigtings, naamlik finansieel (58), produksie (7), bemarking (22), dataverwerking (13), personeel (39), administratief (41) en algemene bestuur (48). Die aantal bestuurders in ander ongedefinieërde rigtings was 49 .

\section{Meetinstrumente}

'n Posvraelys is gebruik om 'n battery van meetinstrumente by die steekproef af te neem.

' $n$ Vraelys bestaande uit vier afdelings (A, B, C en D) is vir die doel van die studie saamgestel. Afdeling $A$ het bestaan uit 31 items wat ten doel had om biografiese inligting omtrent die proefpersone te bekom. Enkele items is uit 'n vraelys wat Coetsee (1973) ontwikkel het, geneem. Verdere items is deur die skrywer bygevoeg. Afdeling B het bestaan uit die Pensacola Z-skaal (Jones, 1957) wat vier "faktore" meet naamlik angs, vyandigheid, afhanklikheid en rigiditeit. Afdeling $C$ het bestaan uit die sogenaamde "Faith in People"-skaal van Rosenberg (1957) wat die mate takseer waarin 'n individu vertroue het in ander individue se betroubaarheid, eerlikheid, goedheid, mededeelsaamheid en broederlikheid. Afdeling $D$ het bestaan uit die Organisasieklimaatvraelys soos ontwikkel deur Gelfand (1972). Hierdie vraelys is ' $n$ aanpassing van die Organisasieklimaatvraelys van Litwin en Stringer (1968) en dek die volgende sewe dimensies: struktuur, betrokkenheid, ondersteuning, affiliasie, burokrasie, standaarde en risikoneming. 
Die funksionele waardes (statistiese kenmerke en so meer) van die verskillende skale word volledig in De Villiers (1990) beskryf.

\section{RESULTATE}

Die resultate van die ondersoek word in vier hoofkategorieë, naamlik biografiese data, vertroue in mense, organisasieklimaat en outoritarisme aangebied.

\section{Biografiese data}

Die tipiese biografiese profiel van die bestuurders wat die steekproef gevorm het, is in Tabel 1 saamgevat.

TABEL 1

BIOGRAFIESE PROFIEL VAN BESTUURDERS IN DIE OPENBARE EN PRIVAATSEKTOR

\begin{tabular}{|c|c|c|}
\hline & Openbare sektor & Privaatsektor \\
\hline Bestuursrigting werksaam & Algemene bestuur & Algemene bestuur \\
\hline Ouderdom (hoogste frekwensie) & $41-45 \mathrm{~J}$. & $41-45 \mathrm{~J}$ \\
\hline Geslag & Manlik & Manlik \\
\hline Hoogste kwalifikasie & B.graad & B.graad \\
\hline Huistaal & Oorwegend Afrikaans & Oorwegend Afrikaans \\
\hline Basiese salaris & R61 $000-70000$ & R61 $000-70000$ \\
\hline Totale vergoedingspakket & R81 $000-90000$ & R81 $000-90000$ \\
\hline Leier in buitemuurse aktiwiteit as kind & Af en toe & Dikwels \\
\hline Leiersposisies gedurende hoërskoolloopbaan & Gemiddeld, 1,6 & Gemiddeld 2,05 \\
\hline Posisie in gesinshiërargie & Oudste kind & Oudste kind \\
\hline Leiersposisies beklee gedurende universiteitsloopbaan & Gemiddeld 0,44 & Gemiddeld 1,37 \\
\hline $\begin{array}{l}\text { Aantal besture van welsyns- en ander organisasies waarop } \\
\text { die afgelope } 5 \text { jaar gedien }\end{array}$ & $1-2$ & $1-2$ \\
\hline Prestasie op hoërskool & Boonste $10 \%$ & Boonste $10 \%$ \\
\hline Prestasie op universiteit & Bogemiddeld & Bogemiddeld \\
\hline Tipe universiteitstudie & Voltyds & Voltyds \\
\hline Aantal jaar in huidige pos & Minder as 2 jaar & Meer as 5 jaar \\
\hline Aantal keer bevorder die afgelope 10 jaar & 2-3 keer & $2-3$ keer \\
\hline Jare werksaam by organisasie & Meer as 20 jaar & Meer as 20 jaar \\
\hline Gesinslewe & Baie gelukkig & Baie gelukkig \\
\hline Kere getroud & 1 & 1 \\
\hline $\begin{array}{l}\text { Aantal sportspanne of verenigings waarvan lid op univer- } \\
\text { siteit }\end{array}$ & $1-2$ & $1-2$ \\
\hline $\begin{array}{l}\text { Aantal sosiale, welsyns- en ander verenigings waarvan tans } \\
\text { lid }\end{array}$ & $1-2$ & $1-2$ \\
\hline $\begin{array}{l}\text { Aantal sosiale, godsdienstige en ander verenigings waarvan } \\
\text { lid op skool }\end{array}$ & $1-2$ & 3-5 \\
\hline Aantal ure per week liggaamlike oefening & $1-2$ & $1-2$ \\
\hline Aantal bestuursvlakke in organisasie & 5,64 & 6,13 \\
\hline
\end{tabular}

Hiërargiese posisie van bestuursvlak wat beklee word (van bo af)

Dit blyk dat, met verwysing na die betrokke steekproef, die biografiese profiel van die bestuurder in die openbare sektor grootliks ooreenstem met dié van die bestuurder in die privaatsektor. Die bestuurder in die privaatsektor het wel as kind meer dikwels as leier in buitemuurse aktiwiteite opgetree, het beduidend meer leiersposisies op hoërskool en universiteit be- klee, was langer in sy huidige pos werksaam, en was meer betrokke by sosiale, godsdienstige en ander verenigings op skool. Aan die anderkant dui die resultate daarop dat bestuurders in die openbare sektor beduidend beter op universiteit gepresteer het. 


\section{Vertroue in mense}

Geen statisties beduidende verskil is gevind ten opsigte van die konstruk "vertroue in mense" in die openbare en die privaatsektor nie. Na hierdie "geen beduidende verskil" word later teruggekom.

\section{Organisasieklimaat}

Wat organisasieklimaat betref is statisties beduidende verskille ten opsigte van die volgende vyf van die sewe dimensies wat die betrokke vraelys aanspreek gevind:

$\begin{array}{ll}\text { - Struktuur: } & \mathrm{F}(1,323)=17,53, \mathrm{p}<0,05 \\ \text { - Affiliasie: } & \mathrm{F}(1,323)=5,19, \mathrm{p}<0,05 \\ \text { - Betrokkenheid: } & \mathrm{F}(1,323)=24,55, \mathrm{p}<0,05 \\ \text { - Burokrasie: } & \mathrm{F}(1,323)=6,42, \mathrm{p}<0,05 \\ \text { - Ondersteuning: } & \mathrm{F}(1,323)=25,30, \mathrm{p}<0,05\end{array}$

Geen statisties beduidende verskil kon t.o.v. standaarde en risikoneming gevind word nie.

Bogemelde bevindinge dui daarop dat bestuurders in die privaatsektor hul organisasies waarneem as synde meer gestruktureerd en meer affiliasiegeoriënteerd te wees, 'n groter mate van betrokkenheid by personeel te openbaar, meer burokraties te wees en om meer ondersteuningsgeoriënteerd te wees.

Hierdie bevindings is teen die verwagting in. Buchele (1977, pp. 194-196) wys bv. daarop dat owerheidsorganisasies meer gestruktureerd en rigied is en dat 'n sterk burokratiese patroon by sodanige organisasies voorkom. Rainey, Backoff en Levine (1976, pp. 233-244) asook Rinehart, Barrel, De Wolfe, Griffin en Spamer (1969, pp. 230-235) meen dat daar in openbare organisasies minder organisatoriese betrokkenheid, asook 'n laer behoefte aan affiliasie by lede van die organisasie is.

Die feit dat daar geen statisties beduidende verskil gevind is ten opsigte van die klimaatdimensies, standaarde en risikoneming nie, is eweneens onverwags aangesien verskeie skrywers (Murray, 1975; Starling, 1982; Buchele, 1977) daarop wys dat daar in openbare sektororganisasies, in teenstelling met organisasies in die privaatsektore, dikwels 'n vaagheid bestaan ten opsigte van organisatoriese en individuele prestasiestandaarde en -doelwitte.

Daar is verwag dat, aangesien die winsmotief ' $n$ groter rol in privaatsektor organisasies speel en daar 'n groter outonomie in bestuursbesluitneming en optrede is (Murray, 1975, pp. 364-371), risikoneming as klimaatdimensie meer beduidend na vore sou kom in hierdie organisasies.

\section{Outoritarisme}

'n Statisties beduidende verskil is gevind tussen die mate van outoritarisme wat deur bestuurders in die openbare en privaatsektor openbaar word $(F(1,323)=3,88$, $\mathrm{p}<0,01)$. Die mate van outoritarisme wat deur bestuurders in die privaatsektor openbaar word, was statisties beduidend hoër as dié wat deur hul eweknie in die openbare sektor openbaar word.

Dit is ' $n$ onverwagte resultaat aangesien dit nie strook met wat, oppervlakkig geoordeel, verwag sou kon word nie, nl. dat bestuurders in die openbare sektor sou neig om meer outoritêr te wees. Dit strook ook nie met die bevindinge van verskeie ander navorsers nie. Rawls (in Rainey, Backoff en Levine, 1976, p. 241) het byvoorbeeld gevind dat persone in openbare organisasies se response op persoonlikheidskale hoër was op dimensies soos dominansie en kapasiteit vir status as hul eweknie in die privaatsektor. Ook Murray (1975, pp. 364-371) wys daarop dat bestuursamptenare in die openbare sektor in hul bestuursoptrede minder buigsaamheid aan die dag lê. Sodanige onbuigsaamheid word deur verskeie ander navorsers (Rokeach, 1948, en Adorno Frenkel Brunswik, Levinson en Stanford, 1950) met outoritarisme in verband gebring. Minton en Schneider (1980, p. 236) toon aan dat persone wat as konvensioneel en rigied getipeer kan word, 'n voorkeur openbaar vir goed gestruktureerde werksomgewings soos wat in die openbare sektor aangetref word. Hierdie siening word deur Tyler (1965, pp. 198-202) bevestig.

'n Moontlike verklaring vir hierdie teenstellende bevinding is dat die doelgerigte, winsgemotiveerde optrede van bestuurders in die privaatsektor gepaard gaan met ' $n$ mate van outoritarisme, terwyl daar in die openbare sektor die afgelope aantal jare weg beweeg is van konvensionele bestuurstyle en meer klem gelê is op deelnemende en demokratiese bestuursoptrede.

Wat die individuele dimensies van die skaal betref, is geen statisties beduidende verskille gevind t.o.v. afhanklikheid, rigiditeit en angs nie. Daar is wel ' $n$ statisties beduidende verskil $(F(1,323)=13,83, p<0,01)$ gevind t.o.v. vyandigheid. Bestuurders in die privaatsektor het $\mathrm{nl}$. ' $\mathrm{n}$ beduidend hoër mate van vyandigheid openbaar. Hierdie bevinding sou eweneens verklaar kon word deur die feit dat die sake-omgewing in die privaatsektor vergeleke met die openbare sektor, meer mededingend is; vandaar die meer "vyandige" optrede van bestuurders.

\section{GEVOLGTREKKINGS}

Die hoë mate van ooreenstemming in die biografiese profiele van bestuurders in die openbare en privaatsektor toon aan dat dieselfde tipe persoon (sover dit agtergrond betref) wat 'n loopbaan in die privaatsektor volg ook as bestuurder in die openbare sektor suksesvol behoort te wees. 'n Moontlike verklaring hiervoor is dat daar in die jongste tyd in Suid-Afrika meer klem geplaas word op deregulering en doeltreffendheid in die openbare sektor en dat, as gevolg van rasionalisasie en beroepspesifieke salarisaanpassings, loopbaangeleenthede in die openbare sektor meer aantreklik is as wat voorheen die geval was.

Uit die feit dat bestuurders in die privaatsektor beduidend meer leiersposisies op skool en tydens hul universiteitsloopbaan beklee het, kan die afleiding gemaak word dat persone met ' $n$ sterk leierskapsoriëntering meer geredelik tot die privaatsektor toetree, moontlik omdat hulle meen dat hulle in dié betrokke omgewing hulself in 'n groter mate sal kan uitleef.

Daar is geen statisties beduidende verskil gevind tussen die openbare en privaatsektor t.o.v. die mate waarin bestuurders vertroue in mense openbaar nie. Hierdie verskynsel kan waarskynlik daaraan toegeskryf word dat in albei sektore daar in die laaste jare in bestuursontwikkelingsprogramme besondere klem op mensoriëntering geplaas is en dat dit skynbaar'n gunstige ontwikkeling gehad het.

Bestuurders in die privaatsektor het geblyk meer outoritêr te wees vergeleke met hul eweknieë in die openbare sektor. Hierdie verskynsel kan waarskynlik daaraan toegeskryf word dat organisasies in die privaatsektor meer op die winsmotief ingestel is. Die sake-omgewing is normaalweg meer kompeterend van aard en doelwitbereiking wat hiermee gepaard gaan, bring waarskynlik 'n meer outoritêre optrede aan die kant van bestuurders in hul besluitnemingsprosesse mee.

Waar organisasies in die openbare sektore oorwegend ingestel is op die lewering van diens aan die breë publiek, is dit moontlik dat bestuursoptrede en besluitneming meer gerig sal wees op die verkryging van konsensus wat uiteraard as 'n meer demokratiese styl getipeer kan word.

In die mate waarin outoritarisme weerklank vind in bestuursoptrede, is daar ' $n$ verskil in die bestuurstyl van bestuurders in die openbare en privaatsektor.

Hoewel die persoonlikheidsprofiel van die bestuurder in die openbare sektor grootliks ooreenstem met dié van die bestuurder in die privaatsektor (soos gemeet deur sommige van die dimensies van die Pensacola Z-skaal) blyk dit tog dat laasgenoemde 'n groter mate van vyandigheid (aggressie) openbaar. Die meer kompeterende aard van die sake-omgewing kan waarskynlik as verklaring hiervoor dien.

Benewens die feit dat organisasies in die privaatsektor meer bestuursvlakke het, is gevind dat hierdie organisasies meer struktuur en burokrasie het, terwyl daar aan die anderkant ook 'n duideliker klimaat van affiliasie, betrokkenheid en ondersteuning blyk te wees.

Dit is moontlik dat bestuurders in die privaatsektor items wat op struktuur en burokrasie betrekking het, met organisasiedoeltreffendheid in verband gebring het - vandaar die hoë tellings. Affiliasie, betrokkenheid, en ondersteuning sou verband kon hou met 'n groter mensgeoriënteerdheid. Hoewel laag, is beduidende korrelasies wel tussen "vertroue 
in mense" en elk van bogenoemde dimensies gevind.

'n Moontlike verklaring vir die verskil in bestuurstyl en die verskil in organisasiefunksionering en klimaat is waarskynlik geleë in die samestelling van die steekproef. Oppervlakkig geoordeel was die organisasies in die privaatsektor, wat in die ondersoek betrek is, groot gevestigde sake-ondernemings met so 'n gevestigde markaandeel dat hulle waarskynlik meer gestruktureerd en selfs meer burokraties gefunksioneer het as kleiner sakeondernemings in 'n hoogs mededingende omgewing. Organisasies in die openbare sektor was in sommige gevalle reeds betrokke by prosesse van rasionalisering en deregulering - wat hul nader aan die privaatsektorbenadering bring.

Sover dit indiensneming en keuring van persone met die oog op bestuursloopbane betref, kom daar uit die resultate sekere riglyne na vore. Organisasies in die privaatsektor kan 'n redelike gewig heg aan die aantal leiersposisies wat kandidate op hoërskool en gedurende hul universiteitsloopbaan beklee het. Indien daar by keuring van persoonlikheidsmeting gebruik gemaak word, kan organisasies in die privaatsektor 'n redelike waarde heg aan persoonlikheidskenmerke soos outoritarisme en vyandigheid (aggressie).

Nuttige inligting het ook na vore gekom uit die organisasieklimaatmeting. In die mate waarin organisasieklimaatdimensies in verband gebring kan word met gehalte van werkslewe, is dit vir organisasies in die openbare sektor van betekenis om daarop te let dat posbekleërs relatief minder ondersteuning ervaar, minder betrokke voel, en nie soveel bevrediging van affiliasiebehoeftes ondervind nie. Hierdie konstrukte behoort in toekomstige organisasieontwikkelingsprogramme opgeneem te word.

Organisasies in die privaatsektor behoort daarop bedag te wees dat, veral wanneer hulle toeneem in grootte en 'n gevestigde markaandeel het, posbekleërs neig om die organisasie as meer gestruktureerd en selfs burokraties waar te neem. Organisasieontwikkelingsprogramme binne organisasies in die privaat sektor behoort hierdie persepsies aan te spreek om te voorkom dat dit negatief op organisasiedoeltreffendheid inwerk.
Rinehart, J.B., Barrel, R.P., De Wolfe, A.S., Griffin, J.E. \& Spamer, F.E. (1969). Comparitive study of need satisfaction in government and business hierarchies. Journal of Applied Psychology, 53(3), 230-235.

Rokeach, M. (1948). Generalized mental rigidity as a factor in ethnocentrism. Journal of Abnormal Psychology, 43, 259-278.

Rosenberg, M. (1957). Occupations and values. Glencoe, Illinois. Free Press.

Starling, G. (1982). Managing the public sector. Homewood, Illinois: Dorsey Press.

Tyler, L.E. (1965). The psychology of human differences. New York: Appleton Century Crofts.

Verster, R. (1980). Personnel Management in public institutions with special reference to municipalities. Department of Industrial Psychology. Personnel Research Division, University of the Orange Free State, Bloemfontein.

\section{VERWYSINGS}

Adorno, T.W., Frenkel-Brunswik, E., Levinson, D.J. \& Sanford, R.N. (1950). The authoritarian personality. New York: Harper.

Buchele, R.B. (1977). The management of business and public organisations. New York: McGraw Hill.

Coetsee, L.D. (1973). 'n Biografiese en psigologiese profiel van 'n aantal Suid-Afrikaanse bestuurders. Ongepubliseerde doktorale proefskrif. Potchefstroomse Universiteit vir Christelike Hoër Onderwys, Potchefstroom.

De Villiers, W.S. (1990). Bestuurstyle in die openbare en privaatsektor van die Suid-Afrikaanse volkshuishouding. Ongepubliseerde doktorale proefskrif. Randse Afrikaanse Universiteit, Johannesburg.

Gelfand, J. (1972). The Modification, development and application of a measure of organization climate and its relationships to higher order needs. Unpublished Masters thesis, University of the Witwatersrand, Johannesburg.

Jones, M.B. (1959). The Pensacola Z Survey: a study in the measurement of authoritarian tendency. Psychological Monogaphs, 71, No. 452.

Litwin, G. \& Stringer, R. (1968). Motivation and organizational climate. Boston, Division of Research, Graduate School of Business Administration, Harvard University.

Minton, H.L. \& Schneider, F.W. (1980). Differential psychology. Monterey: Brooks/Cole.

Murray, M.A. (1975). Comparing public and private management - an exploratory essay. Public Administration Review, 34(4), 364-371.

Rainey, S.G., Backoff, R.W. \& Levine, C.H. (1976). Comparing public and private organizations. Public Administration Review, 36(2), 215-244 